\title{
Karyotyping of Spondias L. (Anacardiaceae) using fluorescent microscope
}

\begin{abstract}
The genus Spondias L. belongs to the Anacardiaceae family and includes 18 species. Cytogenetic studies addressing the genus Spondias are rather few. Previous studies did not include all Spondias species and the chromosome number is questionable due to the fact that poor chromosome counting protocols were used. In this paper, the karyotypes of five Spondias species were studied using fluorescent microscope to provide indepth insights to understanding the cytogenetics and phylogeny of the genus Spondias. The results show that all studied Spondias species have the same chromosome number which is $2 \mathrm{n}=32$ based on all previous morphological and molecular studies, which clearly suggest a very close genetic relationship among Spondias species, and the chromosome numbers reported by various cytogenetic studies.
\end{abstract}

Keywords: spondias, cytogenetics, chromosome numbers, fluorescent microscopy
Volume 7 Issue 6 - 2017

\author{
Mohannad G Al-Saghir \\ Department of Environmental and Plant Biology, Ohio \\ University, Zanesville, USA
}

\begin{abstract}
Correspondence: Mohannad G.Al-Saghir, Department of Environmental and Plant Biology, Ohio University, Zanesville, Ohio, USA, Email al-saghi@ohio.edu
\end{abstract}

Received: October 23, 2017 | Published: December 08, 2017

\section{Introduction}

The genus Spondias L. belongs to the Anacardiaceae family and includes 18 species with at least nine Neotropical species. ${ }^{1}$ Spondias is native to tropical America and Asia, and Madagascar. Spondias has been used as far as 6500 B.C., in the Tehuacán Valley of Mexico. ${ }^{2}$ $S$. mombin L. (Cajá), S. tuberosa Arruda Câmara (Umbu) and $S$. purpurea (Serigüela) are the most economically important species in the genus for agro-industrial applications. Chromosomal data are a valuable resource for cytogeneticists and breeders as they provide better insights into taxonomic and phylogenetic relationships among the species. ${ }^{3,4}$ Cytogenetic studies addressing the genus Spondias are rather limited. Previous studies showed that studied Spondias species were diploids with somatic chromosome number of $2 n=32$. The only cytogenetic data available are the chromosome numbers $(2 n=32)$ of three species: S. pinnata ${ }^{5-7}$ S. mombin ${ }^{8}$ and $S$. tuberose. ${ }^{9}$ Recently, De Souza Alemdia et al. ${ }^{10}$ studied the karyotype differentiation among five Spondias species and the putative hybrid Umbu-cajá. All the studied species and hybrid presented the same chromosome number $(2 \mathrm{n}=32)$ and morphology. Previous studies did not include all Spondias species and chromosome numbers of the different Spondias species are questionable because inefficient chromosome counting protocols were employed. ${ }^{11}$ These protocols are hampered by the small sized chromosomes of Spondias species and a few cell divisions were visible in a single root tip. ${ }^{11}$ The aim of this study was to develop more effective method to resolve the chromosome numbers in Spondias species using fluorescent microscope and provide more insight into understanding the cytogenetic and phylogeny of the genus Spondias.

\section{Materials and methods}

\section{Plant materials}

Leaves from the herbarium specimens of six Spondias specieswere used. The species studied are listed in Table 1. The specimens were obtained from University of Florida Herbarium (FLAS), Gainesville, Florida. For this study, the Sigma Plant Protoplast Digest/Wash Solution protocol (Sigma, St. Louis, MO, USA) was modified as the following: ${ }^{12} 1 \mathrm{~g}$ of dried leaf tissue was collected from each specimen and cut into $1 \mathrm{~mm}$ sections using a sharp blade. The sections were placed in $50 \mathrm{~mL}$ conical vials, each filled with $20 \mathrm{~mL}$ of Plant Protoplast Digest/Wash Solution (Sigma, St. Louis, MO, USA).After being mixed via inversion for $5 \mathrm{~min}$, the Digest/Wash Solution was removed leaving only the leaf tissue. Ten $\mathrm{mL}$ of the digestion enzyme solution was added and mixed via inversion for $2 \mathrm{~min}$. The mixture was gently agitated on the platform shaker for one hour. After $1 \mathrm{~h}$, $50 \mu \mathrm{L}$ of each mixture was diluted into 4 micro centrifuge tubes each containing $450 \mu \mathrm{L}$ of Digest/Wash Solution.

The mixtures were spun at $100 \mathrm{xg}$-forces for $5 \mathrm{~min}$; the supernatant was removed leaving the pellets intact. Twenty $\mathrm{mL}$ of Digest/Wash Solution was added to the pellets and was mixed. The mixture was spun at $100 \mathrm{xg}$-forces for $5 \mathrm{~min}$. The supernatant was removed and $10 \mu \mathrm{L}$ of fixative was added to each pellet; the pellets were resuspended via inversion and chilled on ice for one hour. Then, the mixtures were dropped onto room-temperature slides. The slides were stained with 4'-6-Diamidino-2-phenylindole (DAPI) (Sigma, St. Louis, MO, USA) and placed under fluorescent microscope (Leica, Wetzlar, Germany).

\section{Results and discussion}

The results show that Spondias species are diploid and they have the same chromosome number of $2 n=32$ (Table 1) (Figure 1). This study is the first to report the chromosome numbers using fluorescent microscope and the first to report the chromosome number for all studied species except $S$. mombin. The method was developed initially for Pistacia L. species because root-tips from the field are not possible to obtain and cuttings do not make roots easily. Roots from seedlings are rather small. Moreover, the Pistacia species havevery small chromosomes. ${ }^{12}$ This study shows that the same method can be used successfully to study the chromosome number among Spondias species. Somatic chromosome number of $2 \mathrm{n}=32$ for $S$. mombin has earlier been reported. ${ }^{8,10}$ These findings were supported by the current study (Figure 1). Chromosome number of $S$. purpurea was reported as $2 n=32 .{ }^{10}$ The current study is in agreement with these findings. Moreover, De Souza Alemdia et al., ${ }^{10}$ found that all the analyzed Spondias species exhibited similar karyotypes and small chromosomes. This study provides valuable chromosomal data for potential use by the cytogeneticists and plant breeders. This study 
also provides additional insight into understanding the taxonomic and phylogenetic relationships among Spondias species.

Table I List of Spondias species used; Their chromosome number and plant identification numbers

\begin{tabular}{lll}
\hline Species & $\begin{array}{l}\text { Chromosome } \\
\text { count (2n) }\end{array}$ & Plant ID \\
\hline Spondias mombin L. & 32 & 14803 I \\
Spondias x robe Vrbar & 32 & 179743 \\
Spondias dulcisForst. F. & 32 & 188070 \\
Spondias purpurea L. & 32 & 80867 \\
Spondias radlkoferi J.D. Sm. & 32 & 140725 \\
Spondias laevis Griseb. & 32 & 78925 \\
\hline
\end{tabular}

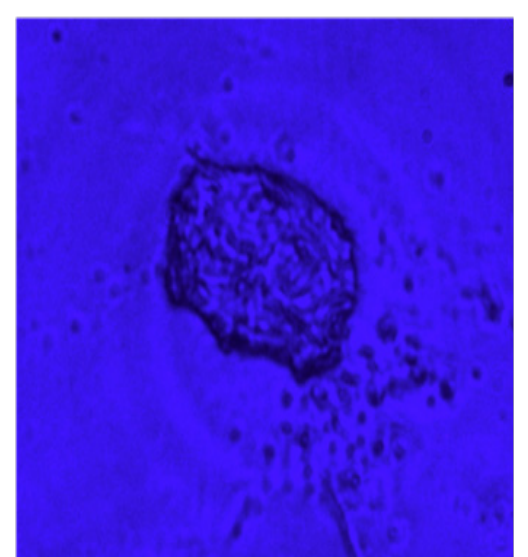

Figure I A typical cell with chromosomes $(2 \mathrm{n}=32)$ of Spondias mombin $\mathrm{L}$.

\section{Acknowledgements}

The author is grateful to Ohio University Zanesville for funding this project. The author is very thankful for University of Florida Herbarium and Manager of collections Kent D. Perkins for loaning the specimens. The author would like to thank Dr. Philip Cantino,
Director of the Bartley Herbarium at Ohio University for his help in sending this loan.

\section{Conflict of interest}

The author declares no conflict of interest.

\section{References}

1. Mitchell JD, Daly DC. A revision of Spondias L. (Anacardiaceae) in the Neotropics. PhytoKeys. 2015;55:1-92.

2. Smith CE. Plant remains. In: MacNeish RS editors. Prehistory of the Tehuacán Valley 5 University of Texas Press, Austin, USA; 1965. p. $220-255$.

3. Raven PH. The bases of angiosperm phylogeny: cytology. Ann Missouri Bot Gard. 1975;62(3):724-764.

4. Stuessy TF. Plant Taxonomy. USA: Columbia University Press; 1990.

5. Mehra PN, Sachdeva SK. Cytological observation on some West Himalayan monocots. Cytologia. 1976;41:31-53.

6. Sarkar AK, Datta N, Chatterjee U, et al. In IOPB chromosome number reports LXXVI. Taxon. 1982;31(3):574-594.

7. Singhal VK, Gill BS. Chromosomal studies in some members of Anacardiaceae. Cytol Genet. 1990;25:36-42.

8. Guerra MS. Citogenética de angiospermas coletadas em Pernambuco. I Rev Bras Genet. 1986;9:21-40

9. Pedrosa A, Gitaí J, Silva AEB, et al. Citogenética de angiospermas coletadas em Pernambuco, V. Acta Bot Brasilica. 1999;13(1):49-60.

10. De Souza Alemdia. Karyotype differentiation among Spondias species and the putative hybrid Umbu-cajá (Anacardiaceae). Bot J Linn Soc. 2007;155(4):541-547.

11. Ila HB, Kafkas S, Topaktas M. Chromosome numbers of four Pistacia (Anacardiaceae) species. J Hortic Sci Biotechnol. 2003;78(1):35-38.

12. Al-Saghir M, Baker S, Pusok R. Effective Method to Resolve the Chromosome Numbers in Pistacia Species (Anacardiaceae). Am J Plant Sci. 2014;5:2913-2916. 